\title{
COTAS RACIAIS - DÍVIDA, REPARAÇÃO E AFIRMAÇÃO
}

RACIAL QUOTAS - DEBT, REPAIR AND AFFIRMATION

\section{Fillipe Gonçalves Araújo ${ }^{1}$, Lúcia Maria Temóteo²}

RECEBIDO EM: 23/08/2020 | ACEITO EM: 14/10/2020

DOI: $10.5902 / 2317175853332$

\section{RESUMO}

O presente trabalho aborda uma política pública brasileira - as Cotas Raciais. O Brasil escravizou índios e negros por centenas de anos. Os descendentes desses grupos são vítimas da brutal desigualdade social e étnica. Desse modo, a resistência e luta dessa população fazem com que o Estado elabore uma série de ações e políticas afirmativas que tem a principal finalidade a reparação de uma dívida histórica, dentre essas ações temos as Cotas Raciais. O objetivo deste trabalho foi de compreender a percepção dos estudantes do ensino superior público, que ingressaram através da ampla concorrência, sobre a importância do sistema de cotas. Trata-se de uma pesquisa de natureza básica, de método qualitativo e de caráter exploratório, sendo realizada com 5 estudantes do curso de Medicina, que ingressaram ao curso por meio de ampla concorrência em uma universidade pública do interior do Nordeste. Os dados foram coletados por meio de entrevistas semiestruturadas e através delas foi observado que os participantes entendem a importância da política, visto que os grupos que fazem uso dela ainda são marginalizados socialmente, entretanto, mesmo com essa concepção, observa-se pouco aprofundamento nas respostas, sendo que se limitaram a falar da dificuldade de inserção desses grupos ao ensino superior e, ainda, utilizando-se de um tom teórico.

Palavras-chave: Psicologia; Política Pública; Educação.

1 ORCID iD: https://orcid.org/0000-0002-2651-1082

Lattes: http://lattes.cnpq.br/9351053501597726. Brasil

2 Lattes: http://lattes.cnpq.br/7584669776057135. Brasil 


\begin{abstract}
The present work addresses a Brazilian public policy - the racial quotas. Brazil enslaved Indians and blacks for hundreds of years. The descendants of these groups are victims of brutal social and ethnic inequality. In this way, the resistance and struggle of this population causes the state to develop a series of affirmative actions and policies that have the main use of repairing a historic debt, among these actions we have as racial quotas. The objective of this work was to understand the perception of students of public higher education, who entered the broad competition, about the importance of the quota system. It is a research of a basic nature, of a qualitative method and of an exploratory nature, being carried out with 5 medical students, who enter the course through wide competition, from a public university in the interior of the northeast. The data were collected through semi-structured interviews and through which it was observed that the participants understand the importance of the policy, since the groups that use them are still socially marginalized, even so with these actions, there is little less in the responses, who measure that they practically limit themselves to talking about the difficulty of inserting these groups in higher education and also, using a theoretical tone.
\end{abstract}

Keywords: Psychology, Public Politic; Education.

\title{
1 Introdução
}

Dias e Miranda (2017) afirmam que as universidades públicas brasileiras apresentam quase totalmente, diante das vagas ofertadas, um preenchimento para alunos oriundos do ensino privado. A conjuntura da educação pública de base em nosso país sempre ${ }^{3}$ foi vulnerável no sentido da qualidade do ensino. A educação básica pública, totalmente fragmentada, faz com que os seus índices caiam de uma forma feroz. Segundo Gaia e outros (2019) o descaso do Estado para com a educação pública no país gera desigualdades, visto que a negligência com que o Estado trata a educação atinge os grupos que estão em situação de vulnerabilidade, em sua maioria, os negros.

Desse modo, pessoas que são privilegiadas financeiramente buscam sanar a falta da educação pública de base e qualidade na educação privada, e pessoas que não têm o mesmo privilégio acabam por usar do ensino público. Em contrapartida, Menezes (2015) apresenta que o ensino superior público brasileiro, principalmente dos centros federais, sempre foi referência na qualidade e na eficácia do ensino, e quem acaba utilizando-se desse ensino são as pessoas que conseguiram ter uma boa base, pois são as únicas que conseguem ingresso, enquanto as que não tiveram as mesmas oportunidades são excluídas.

A exclusão do negro no Brasil não está presente somente nos espaços acadêmicos, mas também em relação ao trabalho, à moradia, ao lazer. Segundo Nascimento (1978 p. 82) "até 1950, a discriminação em empregos era uma prática corrente, sancionada pela lei consuetudinária". Os anúncios que buscavam a contratação de funcionários eram divulgados com a indicação direta de que não eram aceitas "pessoas de cor" e que mesmo com leis que proibiam a discrimi-

3 Segundo dados do Índice de Desenvolvimento da Educação Básica (IDEB), a educação pública do Brasil nos anos finais do ensino fundamental e médio só conseguiu atingir as metas planejadas em 2007, 2009 e 2011. Disponível em: http://ideb.inep.gov.br/resultado/ 
nação, como a lei Afonso Arinos de 1951, que foi reivindicada em paralelo com outras medidas de apoio ao povo negro, esse tipo de postura continuou por muitas décadas, impedindo a população negra brasileira de conseguir chegar a espaços que favoreceriam a sua ascensão ou sobrevivência, e propagando de forma escancarada o racismo que está presente no país até a atualidade.

Gaia e outros (2019) afirmam que em decorrência da escravidão a educação do negro no Brasil apresenta uma série de deficiências, isso ocorre pelo fato dessa população estar situada às margens da sociedade, fazendo com que frequente escolas que também estão nessa mesma situação. Se não é assegurada aos negros uma educação básica de qualidade, isso consequentemente os impedirá de chegar a espaços que foram ocupados, por muito tempo, em sua maioria por pessoas brancas, as universidades, por exemplo.

A partir de muita luta do movimento negro esse cenário começou a mudar e essa população finalmente conseguiu alcançar o início da reparação que deveria ter acontecido há muito tempo. Santos e Barbosa (1999) mostram que, graças ao movimento negro que sempre lutou e buscou a diminuição da desigualdade racial em diversos contextos no Brasil, houve a implantação de políticas públicas que favoreceriam essa população. Porém, as discussões sobre as cotas aconteceram de forma genuína apenas em 2001 quando, segundo Alberti e Pereira (2006), deram-se "quando se preparava um relatório para a III Conferência Mundial de Combate ao Racismo, Discriminação Racial, Xenofobia e Intolerância Correlata". Esse relatório produzido para a conferência trazia de forma muito breve a discussão acerca das cotas raciais e, por mais da pauta ser apresentada de forma rápida nas discussões propostas no relatório, foi a que ganhou mais importância na conferência.

Carmo (2018) reconhece que para o movimento negro o acesso à educação, como as cotas universitárias, é compreendido como uma vitória e como uma obtenção de um direito que por muito tempo foi negado a esse povo. De acordo com Guarnieri e Silva (2017) algumas universidades do Brasil aderiram a um sistema que resguardava $50 \%$ das vagas para pessoas que não apresentavam as mesmas oportunidades diante do acesso ao ensino superior, além de grupos minoritários e oprimidos por questões étnicas e raciais (negros e índios).

Com a adesão do sistema de cotas nas universidades de todo o Brasil, o índice de estudantes de escola púbica, de baixa renda, negros e índios, começou a aumentar e essas pessoas começaram a ganhar espaço nesses ambientes. O objetivo desse estudo foi compreender a percepção dos estudantes do ensino superior público, que ingressaram nesse ensino na modalidade de ampla concorrência, sobre a importância do sistema de cotas. Tratou-se de uma pesquisa qualitativa e exploratória e foi realizada em uma universidade federal do interior do Nordeste com alunos do curso de medicina. A coleta de dados foi feita por meio de entrevistas semiestruturadas.

A Constituição Federal de 1988 afirma que o Estado deve se comprometer para efetivar o acesso de todos a educação, desde as fases iniciais até os 
níveis mais avançados desta, porém coloca em seu inciso $V$ que isso vai ser determinado a partir da capacidade de cada indivíduo. Gaia e outros (2019) abordam que existe um discurso na sociedade brasileira que aponta que no país não existe racismo ou desigualdade racial. Essa é uma construção ideológica que está infundada no mito da democracia racial que tem o principal objetivo de negar a realidade que é visível para toda a população e, principalmente, para a negra: a do preconceito, da falta de oportunidades, das penitenciárias lotadas, da falta de pessoas negras em cargos de poder e em universidades. Além de todos esses aspectos, os negros se deparam com uma visão que nega que tudo isso que não lhes é assegurado não faz parte do racismo e da desigualdade presente na sociedade e fundamentada nesse mito, reforçando no negro um ideal de brancura, como afirma Nogueira (2011, p. 11) "a 'brancura' passa a ser parâmetro de pureza artística, nobreza estética, majestade moral, sabedoria científica etc."

Para Ratts (2011) sempre existiu um grande e visível desconforto acerca da presença de pessoas negras em espaços acadêmicos. Segundo o autor, os poucos negros que já estavam inseridos no universo acadêmico desde a década de 1970 traziam discussões e questionamentos diante desse acesso e fizeram surgir o movimento negro de base acadêmica que desempenhou e promoveu importantes ações que discutiam a presença desse grupo na universidade, debatiam os termos que eram usados nesse espaço para contar a história do povo africano, termos esses que não diferiam dos mesmos termos e padrões com que foram e são contados desde o primeiro contato com a história desse povo no país e que se limita a escravidão, deixando de lado os demais aspectos históricos, bem como religiosos, de luta e resistência. Desse modo, a compreensão e o estudo desse fenômeno fazem-se de extrema relevância e nos leva à seguinte questão: qual a percepção do sistema de cotas para estudantes da rede de ensino superior pública que entraram na modalidade de ampla concorrência?

\section{Referencial teórico}

Machado e Cainelli (2014) aludem que a definição de escravidão é conhecida em todo o mundo como um método de serviço oprimido e forçado em que a independência pessoal não existe. Assim sendo, antes mesmo de o povo africano ser traficado para várias colônias europeias, especialmente o Brasil, e serem privados de sua liberdade, o modelo escravocrata já era utilizado em diferentes contextos históricos da humanidade.

Desde outros períodos da humanidade, a escravidão já estava presente, todavia, de acordo com o período, a execução desta se dava de maneiras distintas. Além disso, Pereira e Rodrigues (2013) destacam que no Brasil a escravidão chega muito antes de a população negra ser traficada. Os colonizadores, depois de inserirem a extração do pau-brasil com os indígenas mediante o 
escambo, tentaram escravizar a população que já habitava no Brasil antes de sua chegada. Entretanto, diversos fatores fizeram com que essa tentativa fosse infeliz. Os indígenas não eram imunes a diversas doenças trazidas pelos europeus e acabavam não sobrevivendo a elas, e aqueles que sobreviviam, fugiam e não eram mais capturados pelo fato de conhecerem bem o território.

Por conseguinte, Machado e Cainelli (2014) ainda nos convidam a pensar que, com o passar do tempo, o negro africano começa a ser traficado para a colônia portuguesa ainda no século XVI. Partindo do pressuposto de que eram considerados uma raça inferior, os africanos chegam ao Brasil para trabalhar na produção de cana-de-açúcar, pois Portugal viu que, produzindo esse produto, poderia exportar para o mercado europeu, e a mão de obra escrava seria responsável por toda essa produção, além de não receberem nada pelo seu trabalho.

Durante o período escravocrata brasileiro, existiram diversas formas de resistência por parte dos negros. Alguns fugiam de seus senhores e formavam, dentro das matas, quilombos, que, com o passar do tempo e o fim da escravidão, foram considerados locais de apoio e de suporte aos negros que fugiam dos engenhos ou que eram libertos, mas que não tinham nenhum lugar para ir. Hagg (2010) denuncia que no decorrer dos séculos em que os negros desembarcavam no Brasil muitos deles entravam em tristeza e profunda melancolia diante do sentimento de saudade do continente africano. Os negros eram arrancados de sua terra, de sua cultura, de suas raízes, e eram inseridos em um local em que todos esses aspectos eram completamente diferentes, gerando adoecimento físico e psíquico, e fazendo com que muitos morressem a partir da enfermidade que ficou conhecida como banzo. Com os quilombos surgiu uma forma de resistência e uma oportunidade do negro poder viver em comunidade, resgatando e permanecendo com os valores e com a diversificada cultura trazida do continente africano. No documentário Ôri4 de 1989, Beatriz Nascimento entende que o quilombo surge a partir da fuga do negro que resiste e que tem consciência de que não tem dono. Esses quilombos, presentes até a atualidade, são considerados como importantes formas de resistência do povo negro no Brasil.

De acordo com Nascimento (1978) no Brasil, existiram diversos quilombos. O quilombo dos Palmares, em especial, chegou a receber mais de vinte mil pessoas e apresentava um sistema produtivo e organizado, bem como uma estrutura política e militar bastante eficazes. O quilombo significa o clamor do povo africano contra o fim de sua cultura naquelas terras estranhas nas quais sofreram tanto.

No ano de 1945, com a redemocratização do Brasil, manifesta-se a chance da população negra adentrar na conjuntura econômica e política do país por meio de ações do Estado, fazendo com que, a partir dessa chance, o movimento negro ganhasse mais força na luta por exigências dessa população, trabalhos voltados para a abolição do preconceito, igualdade social, dentre outros pontos que buscavam o combate do racismo e mudanças na constituição. Nascimento e outros (2004) afirmam que na década de 1990 o movimento negro continua

4 Termo Yorubá, referente a África Ocidental, que significa cabeça ou consciência. 
lutando por políticas que assegurem ações para essa população. Uma manifestação organizada pelo movimento negro no ano de 1995 ganha destaque nacional neste período, a "Marcha Zumbi dos Palmares - contra o racismo, pela cidadania e pela vida", acontece em 20 de novembro de 1995, em frente ao Congresso Nacional em Brasília, e reúne cerca de trinta mil ativistas negros.

Também nesse período, Santos (2010) apresenta que foram instituídas políticas de reserva de vagas para cursos de graduação em algumas instituições de ensino superior em todo o país, como a Universidade do Estado do Rio de Janeiro (UERJ), a Universidade do Norte Fluminense (UENF), Universidade do Estado da Bahia (UNEB) e outras. Essas vagas eram reservadas para estudantes oriundos de escolas do ensino público que se autoidentificassem como afrodescendentes ou índios descendentes.

Conforme Domingues (2005), o primeiro estado a adotar a lei de cotas raciais em sua política de seleção de estudantes foi o estado do Rio de Janeiro como mecanismo de popularização do acesso ao ensino superior. Domingues (2005) afirma que algumas universidades do estado do Rio de Janeiro reservaram $40 \%$ das vagas para alunos negros. Essas instituições eram a Universidade do Estado do Rio de Janeiro (UERJ) e a Universidade Estadual do Norte Fluminense (UENF). Causando polêmica, outras instituições públicas de ensino superior do país adotaram a mesma política implantada pelas universidades do Rio, a exemplo da Universidade de Brasília (UnB).

Menezes (2015) observa que com o passar do tempo e as constantes reinvindicações a um acesso igualitário à educação superior, e em decorrência das discussões realizadas diante desse acesso e dos problemas sociais existentes em nosso país, foi publicada, em 2012, e sancionada pela Presidenta da República Dilma Rousseff, a lei $n^{\circ} 12.711 / 2012$, que determina critérios inclusivos em relação à admissão nas universidades e instituições federais de ensino superior, técnico e médio. Esse regulamento ficou conhecido como a lei das cotas.

Na perspectiva de acesso ao ensino superior, segundo Brasil (2012), a lei determina que deverão ser reservadas $50 \%$ das vagas ofertadas para estudantes que tenham cursado integralmente o ensino médio em escolas públicas e estudantes que sejam provenientes de famílias com renda igual ou inferior a 1,5 salário-mínimo (um salário mínimo e meio). Por fim, a lei acima citada determina que essas vagas também devem ser ocupadas por estudantes autodeclarados pretos, pardos e indígenas.

Dessa forma, Menezes (2015) alega que a lei de cotas se apresenta como uma possibilidade de reparação social e redução de desigualdades que mantêm, em diferentes circunstâncias, grupos distintos. Entretanto, mesmo que a política seja considerada uma forma de diminuir a desigualdade social encontrada em grupos e cidadãos que buscam um acesso justo a educação superior, a lei ainda divide opiniões.

Ladeira e Silva (2018), por sua vez, creem que o sistema de cotas é um método, dentro das políticas afirmativas, que procura reparar um passado dis- 
criminatório de forma específica. O objetivo final de tal método é acelerar um meio de igualdade é destinado a grupos que estão em situação de vulnerabilidade. $O$ sistema de cotas é uma ação afirmativa com a finalidade de corrigir as desigualdades de acesso ao ensino superior e, se não falarmos dessa questão, é o mesmo que fecharmos os olhos para um problema social que atinge, sobretudo, as classes com uma menor condição.

\section{Método de pesquisa}

A pesquisa é de natureza básica, de campo e exploratória, que segundo Cozby (2003) é um estudo que visa a responder questões fundamentais sobre a natureza do comportamento. Segundo Gil (2008), a pesquisa científica básica deve ser impulsionada pelo interesse, e as suas descobertas possibilitam a transmissão e o debate de conhecimento diante de toda a comunidade. O tipo de pesquisa do presente estudo foi a qualitativa. Para Minayo (2001), a pesquisa qualitativa trabalha com o universo de significados, motivos, aspirações, crenças, valores e atitudes, o que corresponde a um espaço mais profundo das relações, dos processos e dos fenômenos que não podem ser reduzidos à operacionalização de variáveis.

A pesquisa foi realizada com estudantes do curso de medicina de uma universidade federal localizada no interior do Nordeste. A princípio, iria abarcar alunos cotistas e não cotistas, porém, em virtude da não aceitação dos alunos cotistas de participarem da pesquisa, ela se deu com alunos não cotistas do curso. Desse modo, foram entrevistados 5 estudantes que não são cotistas e que estão matriculados na instituição. Os critérios de inclusão são alunos que estão matriculados no curso de medicina, que tenham ingressado ao ensino superior sem uso de cotas, raciais e que estão entre o $6^{\circ}$ e o $8^{\circ}$ semestres.

Para o presente estudo, foi utilizado como instrumento uma entrevista semiestruturada que ocorre quando o pesquisador elabora um roteiro prévio, porém, podem ser adicionados elementos no decorrer da entrevista que são oriundos das falas dos entrevistados.

Após avaliação e aprovação do Comitê de Ética e Pesquisa (CAAE $n^{\circ}$ 15327919.1.0000.5180), o pesquisador realizou um levantamento junto ao sistema acadêmico da coordenação do curso com o auxílio de uma funcionária, a fim de identificar alunos que ingressaram por meio da ampla concorrência. Esse levantamento se deu após aprovação e emissão do parecer ético da pesquisa. Após esse levantamento, contatou-se cada um dos participantes, informando-lhes os objetivos da pesquisa e questionando-os acerca do interesse em participar do estudo.

Mediante o interesse em participação do estudo, todos os participantes assinaram o Termo de Consentimento Livre e Esclarecido - TCLE - e foram informados das ressalvas éticas do projeto, bem como foram esclarecidas dúvidas acerca deste. Desse modo, foram realizadas as entrevistas, em seguida foi 
feita a transcrição na íntegra dos dados coletados nas entrevistas e, por fim, foi iniciada a análise dos dados que foram coletados. A partir da análise de conteúdo, que para Bardin (2011 p.47) "é um conjunto de técnicas de análise das comunicações visando a obter por procedimentos sistemáticos e objetivos de descrição do conteúdo das mensagens", foi realizada a análise dos dados coletados.

\section{Resultados e Discussão}

\subsection{Dados Sociodemográficos}

A princípio, foram levantados os dados sociodemográficos dos participantes da pesquisa e uma breve descrição deles. A seguir, estão as categorias que emergiram das entrevistas e uma discussão relacionada a elas.

Tabela 1 - Caracterização dos participantes, cidade, UF, cor, semestre, sexo e idade - transcritos como relatado durante a coleta de dados.

\begin{tabular}{|l|l|l|l|l|l|}
\hline Participante & Participante1 & Participante2 & Participante3 & Participante4 & Participante5 \\
\hline Cidade & Fortaleza & Oeiras & Fortaleza & Boa Viagem & Juazeiro do Norte \\
\hline UF & Ceará & Piauí & Ceará & Ceará & Ceará \\
\hline Cor & Parda & Parda & Branca & Parda & Branca \\
\hline Semestre & $6^{\circ}$ & $6^{\circ}$ & $8^{\circ}$ & $8^{\circ}$ & $6^{\circ}$ \\
\hline Sexo & Masculino & Masculino & Masculino & Feminino & Masculino \\
\hline Idade & 24 anos & 20 anos & 25 anos & 23 anos & 21 anos \\
\hline
\end{tabular}

Participaram da pesquisa 5 estudantes do curso de medicina de uma universidade pública federal do interior do Nordeste e que ingressaram no ensino superior por meio da modalidade de ampla concorrência. Quatro são oriundos de cidades do estado do Ceará, e um, do estado do Piauí. Dos 5 participantes, 3 estão no sexto semestre do curso, e 2, no oitavo, sendo 4 do sexo masculino e uma do sexo feminino, com idades entre 20 e 25 anos.

\subsection{Cotas raciais - equidade, ineficiência e incompreensão}

Equidade, ineficiência e incompreensão foram 3 categorias que emergiram das falas dos participantes no início das entrevistas e que merecem ser ressaltadas e analisadas.

Referindo-se à equidade, o participante 2 ressalta: "Eu entendo que é como uma forma de equidade. Colocar conceito, a forma que a gente aprendeu, tratar os diferentes de formas diferentes para que alcancem a igualdade". O participante 1 coloca que as cotas "seriam uma maneira de você integrar um grupo social de pessoas, no caso, negros, que eles têm um histórico de marginalização, tá muito atrelado a sua raça por causa da história do Brasil, que 
sempre segregou os negros e que é uma maneira dessas pessoas ingressarem mais no ensino superior". E, segundo o participante 5 , "todos esses posicionamentos são tentativas de democratizar o acesso ao ensino".

Desse modo, o participante 3 ressalta a ineficiência do sistema de cotas diante do público que deveria atender: "A história diz que a população negra ainda é marginalizada e a gente vê realmente a predominância. Na nossa sala, não tem uma pessoa negra, apesar de terem as cotas para negros [...]". E complementa: "A lei é muito abstrata [...] Eu percebo que, em minha turma, as pessoas que entraram fazendo uso das cotas raciais não seguem um parâmetro ou trazem características de pessoas de cor. Não tem nenhuma pessoa negra em minha turma, pode ter pessoas autodeclaradas negras, mas negros mesmo não, por isso eu acho que existe uma falha [...]". O participante 5 coloca que "[...], considerando que pardos entram nas cotas, dá para identificar na minha turma pessoas, sim, só que entra o negócio das fraudes, que tem gente que não tem aparência de pessoas cotistas, e se autodeclaram." O participante 3 complementa: "[...] a lei é um pouco falha nesse sentido, então acho que deveria ter um filtro maior. Se houvesse uma reformulação onde houvesse uma espécie de banca para avaliar, como existe em outras faculdades, seria fundamental".

Com relação à incompreensão, a participante 4 expõe: "[...] Eu estava no vestibular e eu lembro que foi uma bagunça na minha cabeça de como era que ia ficar, até pensava que ia tirar as vagas de quem era da ampla concorrência, só que depois eu fui entender; realmente era algo que deveria ter sido feito há algum tempo".

A partir das falas dos participantes podemos perceber que todos eles veem as cotas como uma forma de equidade diante do acesso ao ensino superior para pessoas que sofreram no passado, e esse sofrimento levou essas pessoas a uma condição de marginalização na sociedade. Com isso, eles não identificam uma predominância de pessoas nessa condição em seu curso ou em suas turmas, o que os leva ao questionamento de saber se as cotas estão beneficiando quem realmente deveria ser beneficiado.

Desse modo, é observado, diante da fala dos participantes, que a lei é ineficiente para as pessoas que estão fazendo uso dela. Diversas universidades do Brasil usam o critério de autodeclaração como forma de ingresso de candidatos por meio de cotas raciais, no entanto, existem outros critérios que, segundo Marques e Brito (2015), foram reivindicados por líderes do movimento negro na Universidade Estadual do Mato Grosso do Sul (UEMS), onde, diante de muitos casos de não negros que se autodeclaravam negros, tinham acesso aos cursos na instituição por meio das reservas de vagas para pessoas desse grupo.

Em virtude de inúmeras denúncias de alunos negros que não aceitaram essa situação, a UEMS adotou o critério dos traços fenotípicos para todos os candidatos que optassem pelo ingresso por meio de cotas raciais. Marques e Brito (2015) observam que, a partir disso, bancas que são formadas com servidores da instituição, associações de comunidades quilombolas, pesquisadores de outras universidades que estudam as ações afirmativas e relações étnico-raciais come- 
çaram a avaliar os traços dos candidatos cotistas, e isso favoreceu uma mudança no perfil dos alunos que ingressam por meio das cotas raciais na instituição.

A polêmica gerada no período em que a lei de cotas foi sancionada levou a uma série de más compreensões a partir da forma que ela seria efetivada. Essas dúvidas geraram muita incompreensão por parte dos estudantes que não seriam contemplados com a política, e isso fez com que eles acreditassem que as cotas iriam retirar os direitos ou as vagas por meio das quais eles tinham acesso ao ensino superior. Essa má compreensão relacionada às cotas faz com que, ainda hoje, encontremos pessoas que têm um entendimento totalmente equivocado acerca do real objetivo do sistema. Não existem cotas direcionadas somente à questão étnico-racial. A lei é bastante clara no que diz respeito a isso, e todas as cotas raciais estão em paralelo com o tipo de educação que o sujeito teve durante o ensino médio de base, ou seja, as cotas raciais estão atreladas à educação de base que o sujeito teve e resguarda isso para aqueles que vieram de uma condição de educação pública.

\subsection{Educação de base fragmentada e desigualdade social}

Na sequência da entrevista, foram observadas e identificadas duas categorias: a educação de base fragmentada e a desigualdade social. Desse modo, o participante 1 aponta que, "no contexto da educação brasileira, a gente não priorizou muito a educação de base, até hoje acho que não prioriza, e eu acho que as cotas são, sim, necessárias no contexto em que a gente está hoje, [...] mas o ideal seria você ter um investimento maior na educação de base, principalmente na educação pública [...]". Ele ainda complementa: "Acho que, talvez, a política seja necessária por bastante tempo [...]. Se tivéssemos uma educação de base pública semelhante à educação privada, eu acho que elas tenderiam a não ser mais necessárias". O participante 3 concorda com o colega em relação à educação básica, porém, acrescenta que, "como tem também a questão da dívida histórica e a marginalização da pessoa negra, a cota racial deverá permanecer". A participante 4 ressalta que há diferença de qualidade entre escolas públicas de ensino básico em relação a escolas particulares, e que as primeiras oferecem menos oportunidades para os alunos.

Com relação à desigualdade social, o participante 2 coloca que "[...] com certeza existe uma grande reparação histórica para com as pessoas negras, que, querendo ou não, ainda se encontram, pelas próprias estatísticas, dentro da maior taxa de analfabetismo, e a maior parte dessas pessoas se encontram em ambientes menos propícios, seguros e confortáveis [...]". O participante $5 \mathrm{com}$ plementa que "[...] as cotas raciais são necessárias, porque, devido a toda a questão histórica, as pessoas enfrentam problemas diferentes, então é uma tentativa de compensar tudo que essas populações vêm sofrendo por tanto tempo".

A maioria dos participantes apresentaram, em suas falas, críticas à desigualdade da educação pública com relação à privada, e que, se houvesse me- 
Ihora na primeira ou uma certa igualdade, as cotas não seriam mais necessárias. Entretanto, mesmo que a educação pública mostrasse a mesma qualidade da educação privada, ainda haveria desigualdade e dificuldades para negros e indígenas ingressarem no ensino superior, porque ainda estariam presentes outros fatores, como a discriminação, a falta de oportunidades, a desigualdade social e a dívida histórica que se tem com esses grupos, principalmente os negros que ainda são vistos, de uma forma velada, como pessoas inferiores.

Com o fim da escravidão e sem suporte do Estado, os negros que, por mais de 300 anos, foram escravizados, passam a ocupar áreas próximas a morros, e essa ocupação reflete até hoje nos índices de pessoas negras que vivem em favelas, comunidades e morros. Esse reflexo histórico nos leva a compreender e sinalizar as consequências que esse período trouxe para a população negra e como esses fatos influenciaram nas oportunidades que essas pessoas têm nos dias atuais.

Essa série de questões que os indivíduos negros e indígenas vivem reflete na qualidade de vida de cada um deles, visto que eles já se encontram em uma situação de marginalização, e, além disso, essas condições fizeram com que eles fossem excluídos de vários espaços, como cargos de grande notoriedade, e privados de direitos que não lhes foram assegurados, como a educação superior.

A fragmentação e o déficit da educação pública de base atingem todos os indivíduos que fazem uso dela, e a maior parte dessa população é negra. A cada dia, a educação brasileira está cada vez mais precária e quem sofre com isso são as pessoas pobres que, em sua maioria, são pessoas negras. Araújo (2014) afirma que as desigualdades sociais e raciais refletem na educação e influenciam de forma negativa no acesso, na permanência e no resultado de grupos que são historicamente discriminados, principalmente negros e indígenas, em todas as modalidades de ensino.

Desse modo, a falta desses grupos não está presente apenas em contextos de educação superior, mas também em outras modalidades de ensino, que vão desde os anos iniciais da escola regular até a educação superior. Isso reflete significativamente na quantidade de pessoas desses grupos que não são sequer alfabetizadas e que não conseguem o mínimo de formação escolar. Essas pessoas vivem, em sua grande maioria, em situações de pobreza, vivendo em periferias uma realidade cruel que Ihes deixa a limitada escolha entre estudar e trabalhar para se alimentarem.

Além de uma reformulação em nossa educação básica, que é fragmentada, é necessário que exista uma diminuição ou exclusão dessa desigualdade social, que é completamente visível em nosso país. A educação de base deve, com toda certeza, ser reformulada e apresentar qualidade, porém, paralelamente a isso, também se requer o mesmo com a condição social de muitos brasileiros e brasileiras que vivem em situação de pobreza e de marginalização, que carecem por parte dos governantes posicionamentos e ações urgentes em defesa das cotas. Em se tratando da sociedade como um todo, é necessário que haja uma mudança acerca do comportamento que é apresentado à frente 
da população negra do país, que ainda sofre com discriminação, preconceitos e atitudes que não são aceitáveis, tampouco justificáveis.

\subsection{Impacto gerado pelas cotas raciais}

O participante 2 diz que "[...] as cotas igualam essa situação, porque, se com as cotas a gente já vê uma população tão pequena nas universidades, principalmente as públicas que deveriam ser mais acessíveis, imagina sem [as cotas]". O participante 3 ressalta: "[...] Na minha sala, o primeiro da turma é cotista".

O participante 4 pontua que "Outras pessoas veem as cotas como uma forma de facilitar ou então como tipo, veem com outros olhos. Veem que aquela pessoa entrou por cota e fica olhando para aquela pessoa como se ela fosse menor ou como se não tivesse direito de estar ali, que está ali só porque baixou a nota, só tá ali porque teve um meio". E complementa: "Se a maioria das pessoas tem esse pensamento de que baixou a nota para entrar, ela está mais para segregar, mas se a maioria pensa que elas estão ali para compensar, acho que essa é a palavra, por agora e a longo prazo, isso a gente sabe que melhoraria, mas, para igualar, seria uma coisa muito utópica".

O participante 5 diz que "[...]não existe essa cota, todas são vinculadas à escola pública, então ela é muito mais pra igualdade, e a ideia de segregação é muito errada" e finaliza "É muito improvável que as cotas acabem; quase impossível, porque é uma coisa muito distante da nossa realidade e isso está atrelado a toda a história do Brasil, que foi desde a escravidão, porque, se pararmos pra pensar, o negro está mais perto da escravidão do que sem".

Desde 2012, período em que o sistema foi aprovado, a população negra, indígena, parda e de escola pública ingressa no ensino superior, porém ainda sofre com desigualdades, preconceito e marginalização. Desse modo, a política se faz necessária até que essas pessoas tenham os mesmos acessos e direitos que pessoas que são privilegiadas possuem.

Ladeira e Silva (2018) refletem que as cotas são medidas de restauração paliativas e pertencem à mudança. Essa mudança acontece de forma vagarosa, contudo, não deixa de ser base para novas transformações. Introduzir as classes menos favorecidas no ensino superior é deixar que todos tenham chance de adentrar a esse nível de educação.

A educação superior pública foi, por muito tempo, dominada pela elite, que era quem possuía subsídios para chegar a esse espaço. $O$ sistema de cotas surge como uma forma de, mesmo que aos poucos e de forma um pouco vagarosa, quebrar essa situação, pois a educação é um direito de todos e, com ela, pode haver muitas transformações na vida de todos os sujeitos que tem esse acesso.

A maior parte da população no Brasil é negra, porém não se encontra sequer um terço desse público no contexto universitário, o que nos faz refletir sobre os tipos de oportunidades que essas pessoas não tiveram e não têm. Sendo assim, a política de cotas surge como uma forma de inseri-las nesse con- 
texto, fazendo com que tenham acesso a um cenário que, por várias gerações, não possuiu nenhum tipo de representação.

\section{Considerações finais}

O Brasil é um país completamente diverso em questões raciais e foi um dos últimos a colocar fim na escravidão de negros africanos, que eram retirados de seu continente para serem tratados como produto no outro lado do oceano. Em 13 de Maio de 1888, foi decretada a Lei Áurea, que colocou fim na escravidão do povo negro no Brasil. De maneira formal, a abolição decretou o término da escravidão no país, porém a população negra ficou prisioneira das consequências desse período. Preconceito, pobreza, falta de oportunidades e direitos que deveriam terem sido respaldados pelo estado, tudo isso levou o povo negro a viver às margens da sociedade, que os oprimiu por anos com a escravidão e continuou oprimindo com o racismo. Os negros estavam livres, porém não lhes foram assegurados políticas e direitos que fizessem com que eles pudessem ter uma vida digna.

O sistema de cotas no Brasil é uma política pública que, desde sua aprovação e implantação, vem causando uma série de polêmicas e discussões a respeito. A educação, de acordo com a Constituição Federal, é um direito de todos, e as cotas surgem para assegurar tal direito a pessoas que não foram favorecidas com uma educação básica de qualidade.

Com a pesquisa, foi possível entender a percepção que estudantes de um curso considerado elitizado têm acerca de uma ação afirmativa que gerou e ainda gera uma série de polêmicas e questionamentos. Diante das entrevistas, foi notório que os estudantes que ingressaram no ensino superior por meio da ampla concorrência entendem que a política de cotas raciais é importante para que pessoas negras, indígenas e pardas, que vêm de uma condição de educação pública, ingressem no ensino superior e tenham acesso a essa educação.

Também foi possível perceber, a partir das falas dos participantes, que eles apresentam um conhecimento muito teórico acerca do tema, pelo fato de estudarem e conhecerem a política, porém, são falas técnicas, de pessoas que não vivem ou não conhecem a realidade dos sujeitos que são contemplados com a política e que são limitadas diante da educação que as pessoas cotistas tiveram, e que não focam também na condição econômica e social que essas pessoas vivem na sociedade diariamente. Entretanto, segundo os participantes que falaram a partir da realidade da instituição em que estão inseridos, a política possui algumas lacunas no sentido da eficácia que está sendo aplicada, todavia, isso não é uma regra e não reflete de forma geral.

A questão da autodeclaração faz com que, em alguns casos, exista o uso indevido da política por parte de pessoas que não possuem características e traços que são equivalentes aos de pessoas negras, pardas ou indígenas, e isso gera uma diminuição, cada vez mais evidente, na permanência e na presença de indivíduos desses grupos na educação superior. 
Pesquisar acerca do tema proporcionou observar que parte da população que ingressou no ensino superior de uma outra forma, no caso, ampla concorrência, entendem que, mesmo com políticas públicas que favorecem o acesso de grupos discriminados ao ensino superior, eles ainda são minoria e não estão tão representados em cursos que são considerados elitizados, como medicina. Isso está relacionado a alguns fatores que vão desde a conclusão dessa população no ensino básico, que, em sua maioria, não conseguem concluir essa etapa, até mesmo na questão da autodeclaração de candidatos não negros que usam a política de forma indevida e tiram o direito das pessoas que realmente deveriam serem contempladas por ela.

O povo negro foi escravizado por anos, e essa escravidão permanece até hoje, porém de uma forma velada e diferente de como era outrora. Pessoas assumem os lugares que deveriam ser de negros, e, mesmo não pertencendo àquele grupo, impedem que o negro e os demais grupos minoritários tenham acesso a um direito que é básico: a educação. Isso não difere muito dos tempos de escravidão, em que os negros eram privados de outros direitos básicos por uma população branca que, por se sentir superior, não se importava com esses enquanto seres humanos.

Já se passaram quase 10 anos desde a implantação da política de cotas, e, com isso, haverá uma avaliação dos resultados que ocorreram com sua implantação. Essa avaliação será realizada com base nas estatísticas que as pessoas que foram contempladas com a política tiveram nesses anos e se a política necessita de alguma reformulação frente aos resultados que foram obtidos nesse tempo. Esses resultados serão feitos a partir do percentual de negros, pardos e indígenas que ingressaram no ensino superior desde a implantação do sistema.

Em virtude da atual conjuntura política do país, não se pode negar que a política de cotas, assim como tantas outras que foram criadas como forma de favorecer o ingresso de pessoas que até então não possuíam esse acesso ao ensino superior, como FIES, ProUni, Ciências sem Fronteiras, sofreram e sofrerão cortes ou foram e serão excluídas. Existe uma ameaça ao sistema de cotas, justamente em decorrência da postura do atual governo, que não prioriza políticas que beneficiem grupos minoritários ou marginalizados, reafirmando, assim, o cenário de um país racista e preconceituoso, um retrocesso que aponta a volta da concepção de que quem pode ser médico, cientista, juiz, psicólogo é a elite brasileira.

Como a amostra do estudo não foi composta por indivíduos que precisaram das cotas raciais para ingressar ao ensino superior, os resultados se limitam à concepção de pessoas que não conhecem a vivência dos grupos que precisam dessa política para ingressar neste espaço. Entretanto, foi possível compreender que as cotas são, sim, uma forma de reparação diante de uma dívida resultante de privações impostas a um grupo e elas afirmam que todas as pessoas desse grupo excluído têm o direito de ingressar em qualquer espaço elitizado, fazendo com que, por meio do acesso à educação superior, 
os negros, indígenas e pardos transformem e mudem o cenário de suas vidas e do seu povo. Elas são símbolo e resultado de anos de luta e de movimentos que sentem o desejo e a necessidade de mudar a situação de desigualdade, a exemplo do movimento negro. Com isso, as cotas raciais são uma forma de sanar a dívida, reparar e reafirmar que o negro, o indígena e o pardo podem chegar à educação superior, mesmo que de maneira lenta. No entanto, após esse ingresso, é necessário que sejam asseguradas condições, desde as de trabalho até as de aceitação social de pessoas desse grupo em cargos de notoriedade, pois, no Brasil, ainda existe muita discriminação e espanto diante de situações como essa, comprovando, dessa forma, que isso é só o começo de uma batalha a qual vem sendo travada desde o fim da abolição.

\section{Referências}

AlBERTI, V., \& PEREIRA, A., A. A Defesa das Cotas como Estratégia Política do Movimento Negro Contemporâneo. Estudos Históricos. v. 1, n. 37, p. 143-166, 2006

ARAÚJO, J., A. Educação e Desigualdade: A conjuntura atual do ensino público no Brasil. Revista Direitos Humanos e Democracia, v. 2, n. 3, p. 125-157, 2014

Bardin, Laurence. Análise de conteúdo. 1. ed. São Paulo, Almedina, 2011.

CARMO, N., A. O movimento negro e suas contribuições para a implementação do sistema de cotas raciais. IN: VI Seminário CETROS: crise e mundo do trabalho no Brasil, 2018. Anais 2446-8126. Fortaleza.

COZBY, Paul C. Métodos de pesquisa em ciências do comportamento. 1. ed. São Paulo, Atlas, 2003.

DIAS, E. \& MIRANDA, R., L. Educação: parâmetros entre as escolas públicas e privadas do Brasil. Psicologia Escolar e Educacional, v. 21, n. 2, p. 112-120, 2017.

DIA A DIA DA EDUCAÇÃO - CADERNOS PDE. O Trabalho Escravo no Brasil: do período colonial aos dias atuais, 2014. Disponível em: http://www.diaadiaeducacao.pr.gov.br/portals/cadernospde/pdebusca/ producoes_pde/2014/2014_uel_hist_artigo_marli_aparecida_machado.pdf. Acesso em 17 fev. 2019.

DOMINGUES, P. Movimento Negro Brasileiro: história, tendências e dilemas contemporâneos. Dimensões: Revista de História da UFES, v. 3, n. 21, p. 1-24, 2008.

GAIA, R., S., P., VITÓRIA, A., S., CANDIDO, T., P. \& SCORSOLINI-COMIN, F. A nova política dos velhos tempos: reflexões sobre a construção de um projeto de nação. Revista Áskesis, v. 8, n. 1, p. 40-55, 2019

GIL, Antônio Carlos. Como elaborar projetos de pesquisa. 4. ed. São Paulo, Atlas, 2008.

GUARNIERI, F., V. \& SILVA, L., L. Cotas Universitárias no Brasil: Análise de uma década de produção científica. Psicologia Escolar e Educacional, v. 21, n. 2, p. 183-193, 2017.

HAGG, C. A saudade que mata. Revista Pesquisa FAPESP, v. 2. 172, p. 86-89, 2010.

ÍNDICE DE DESENVOLVIMENTO DA EDUCAÇÃO BÁSICA. Resultados e Metas, 2020. Disponível em: http://ideb. inep.gov.br/resultado/. Acesso em 30 set. 2020

MARQUES, E., P., S. \& BRITO, I., A., M. Os candidatos aprovados pelo regime de cotas raciais e os conflitos sobre a identidade negra na banca avaliadora de fenótipo. In: $37^{\text {a }}$

REUNIÃO DA ANPEd, 2015. Anais 2447-2808. Florianópolis.

MENEZES, P., D., L. Reflexões sobre o sistema de cotas no Brasil. Revista Lugares de Educação, v. 5, n. 11, p. 147160,2015

MINAYO, Maria Cecília de Souza. Pesquisa Social: Teoria, método e criatividade. 18. ed. Petrópolis, Vozes, 2001.

NASCIMENTO, Abdias. O Genocídio do Negro Brasileiro: o processo de um racismo mascarado. 1. ed. Rio de Janeiro, Paz e Terra, 1978 
COTAS RACIAIS - DÍVIDA, REPARAÇÃO E AFIRMAÇÃO

NOGUEIRA, I., B. O corpo negro: sentidos e significados. Revista do núcleo de estudos afro-asiáticos da UEL, V. 1, n. 1, p. 10-14, 2011.

NASCIMENTO, A., IGNÁCIO, J., \& PINHEIRO, F. Das Ações Afirmativas dos Movimentos Sociais às Políticas Públicas de Ação Afirmativa: O Movimento dos Cursos Pré-Vestibulares Populares. O público e o privado. Revista de pós-graduação em Sociologia da Universidade Federal do Ceará, v. 1, n. 3, p. 189-205, 2004.

PEREIRA, N., T., B. \& RODRIGUES, Y., T., D. Trabalho escravo no Brasil: Os reflexos da antiga legalidade na escravidão contemporânea. IN: XXIII Encontro Nacional do CONPEDI, 2013. Anais 978-85-68147-08-5. Florianópolis.

RATTS, A. Corpos negros educados: notas acerca do movimento negro de base acadêmica. Revista do núcleo de estudos afro-asiáticos da UEL, v. 1, n. 1, p. 28-40, 2011.

SANTOS, S., A. Políticas públicas de promoção da igualdade racial, questão racial, mercado de trabalho e justiça trabalhista. Revista do Tribunal Superior do Trabalho, v. 76, n. 3, p. 72-105, 2010.

SANTOS, J., R. \& BARBOSA, W., N. Atrás do muro da noite dinâmica das culturas afro-brasileiras. Ministério da Cultura: Fundação Cultural Palmares, v. 1, n. 3, p. 141-157, 1999. 